\title{
Erratum to: Sequential (hFSH + recFSH) vs homogenous (hFSH or recFSH alone) stimulation: clinical and biochemical (cumulus cell gene expression) aspects
}

Timur Gurgan • Debbie Montjean • Aygul Demirol •

Moncef Benkhalifa • Yves J. R. Menezo

Published online: 5 August 2014

(C) Springer Science+Business Media New York 2014

Erratum to: J Assist Reprod Genet (2014) 31:657-665

DOI 10.1007/s10815-014-0208-1

The original version of this article unfortunately contained a mistake. Moncef Benkhalifa was inadvertently omitted. The update is provided here.

The online version of the original article can be found at http://dx.doi.org/ 10.1007/s10815-014-0208-1.

T. Gurgan

Department of Ob\&Gyn, Faculty of Medicine, Hacettepe University,

Ankara, Turkey

T. Gurgan · A. Demirol

The Gurgan Clinic, 06540 Ankara, Turkey

D. Montjean

Service de Médecine et Biologie de la Reproduction, 26 Boulevard

de Louvain, 13285 Marseille, France

M. Benkhalifa

ATL R\&D Laboratory, 78320 La Verriere, France

Y. J. R. Menezo $(\square)$

Laboratoire Clément, 17 Avenue d'Eylau, 75016 Paris, France

e-mail: yves.menezo@gmail.com 